\title{
A construção do ponto de vista em comentários on-line no Facebook
}

\author{
Denise Lima Gomes da Silva*
}

Resumo: Partindo do fenômeno linguístico do dialogismo, este artigo apresenta uma análise das formas de construção do ponto de vista no gênero digital comentário on-line, tendo como aporte teórico-metodológico a Análise Dialógica do Discurso (BAKHTIN, 2016, 2015, 2011; VOLÓCHINOV, 2017, 2013). O corpus da pesquisa é composto por comentários on-line coletados a partir de publicações da revista Veja em sua página no Facebook. Dos resultados, a análise permite mostrar os diferentes mecanismos de interação entre o enunciador e a palavra do outro na elaboração do ponto de vista, evidenciando relações axiológicas dialógicas marcadas entre distanciamentos e/ou aproximações valorativos.

Palavras-chave: Língua. Dialogismo. Ponto de vista. Interações digitais.

Abstract: Through the lens of the linguistic phenomenon of dialogism, this article presents an analysis of the ways in which point of view (POV) is constructed in the online comment genre, supported by the theoretical and methodological approach from the Dialogic Analysis of Discourse (BAKHTIN, 2016, 2015, 2011; VOLÓCHINOV, 2017, 2013). The research corpus is composed by online comments extracted from the comments section of Veja Magazine's posts on Facebook. The results make it possible to demonstrate the diverse mechanisms of interaction between the enouncer and the other's word that operate on the elaboration of point of view, highlighting axiological dialogical relations imprinted amidst the evaluative convergence and/or divergence of statements.

Keywords: Language. Dialogism. Point of view. Digital interactions.

Zusammenfassung: Hinsichtlich dem linguistischen Phänomen der Dialogizität präsentiert diese wissenschaftliche Arbeit eine Analyse zu den Arten von der Konstruktion der Sichtweisen in der Sprechgattung „Online-Kommentar“ (online comment) vor dem Hintergrund des theoretischen und methodologischen Rahmens der dialogischen Sprechanalyse (BAKHTIN, 2016, 2015, 2011; VOLÓCHINOV, 2017, 2013). Das Textkorpus der Untersuchung umfasst einige Online-Kommentare, die einigen Postings des Nachrichtenmagazins „Veja“ zu seiner Facebookseite entnommen wurden. Die Ergebnisse der Analyse zeigen verschiedene Mechanismen der Interaktion zwischen den Sender und das fremde Wort, die an der Entwicklung der Sichtweise arbeiten. Diese Mechanismen betonen axiologische dialogische Beziehungen, die zwischen Annäherungen und/oder Distanzierungen von den fremden

\footnotetext{
* Doutora em Letras pela Universidade Federal da Paraíba (UFPB) com Pós-Doutorado em Ciências da Linguagem pela Universidade Católica de Pernambuco (UNICAP). http://orcid.org/oooo-0003-4093-5866 / E-mail:dslima@gmail.com
}

Este artigo está licenciado sob forma de uma licença Creative Commons Atribuição 4.0 Internacional, que permite uso irrestrito, distribuição e reprodução em qualquer meio, desde que a publicação original seja corretamente citada. https://creativecommons.org/licenses/by/4.0/deed.pt_BR. 
Äußerungen stattfinden.

Stichwörter: Sprache. Dialogizität. Sichtweise. Digitale interaktion.

\section{Considerações iniciais}

O presente artigo objetiva analisar a construção do ponto de vista (PDV) no gênero digital comentário on-line, a partir do fenômeno linguístico do dialogismo, tomando como aporte teórico metodológico o percurso da Análise Dialógica do Discurso (ADD). De acordo com os linguistas russos, Volóchinov (2017, 2013) e Bakhtin (2016, 2015, 2011), a língua é, em sua essência, dialógica e o signo é, por natureza, ideológico. Nesse sentido, todo discurso é determinado pelo contexto ativo e responsivo e todo enunciado é pleno das palavras dos outros em graus vários de alteridade. Nenhum dizer é, portanto, gratuito, pois, em todo enunciado, habita um horizonte valorativo do enunciador.

Dessa forma, levando em consideração o horizonte valorativo do enunciador, o ponto de vista é construído no processo de retomada do discurso do outro. Estudos como os de Cunha $(2015,2014)$ mostram que, nos gêneros digitais, a circulação discursiva é incessante: as formas e os indícios de retomada/modificação dos discursos circulantes estão ligados aos modos como os enunciadores reorientam os discursos circulados e, nesse movimento de reinterpretação, elaboram o seu ponto de vista.

É, portanto, neste contexto interativo que buscamos observar, a partir das relações dialógicas, os modos de valoração orientadores no ponto de contato com o discurso do outro, cuja retomada delineia o PDV do sujeito-enunciador. De início, discutiremos as noções de língua, dialogismo e ponto de vista, e, em seguida, analisaremos o corpus constituído pelo gênero comentário on-line. O comentário e suas respectivas réplicas foram motivados pela postagem publicada na página do Facebook da revista Veja, no dia 17 de abril de 2019. A publicação aborda a declaração da ministra da Mulher, da Família e dos Direitos Humanos, Damares Alves, sobre a deputada federal Tabata Amaral, na ocasião em que, na presença da deputada, a ministra afirma: "Que deputada linda. Só de você já estar aqui. Não precisava nem abrir a boca.”. O post da 
Veja rendeu, até o momento da coleta dos dados ${ }^{1}$, 1,8 mil comentários e 659 compartilhamentos.

\section{Dialogismo e ponto de vista}

Em Marxismo e Filosofia da Linguagem, Volóchinov (2017), ao propor uma reflexão sobre a linguagem, retoma duas correntes paralelas e antagônicas do pensamento filosófico linguístico vigentes em sua época: o subjetivismo individualista e o objetivismo abstrato. Essas duas tendências são fundamentais como ponto de partida para a leitura sociológica da linguagem apresentada pelo pensador russo.

O subjetivismo individualista, cujo representante mais significativo Volóchinov entende ser Humboldt, concebe a linguagem como o conjunto de todos os fenômenos linguísticos, centrada no ato individual criativo do discurso, ou seja, a arena do signo é a psique individual. Para explicar um fenômeno linguístico, seria necessário olhar para o ato de criação individual, pois as leis que regem a criatividade linguística seriam as leis da psicologia individual. Nessa perspectiva, a língua não é um produto pronto, mas sim uma atividade, um processo contínuo.

O objetivismo abstrato tem como principal representante, no entendimento de Volóchinov, as ideias de Ferdinand de Saussure. Volóchinov (2017) critica a ideia de uma língua como sistema estável, fixo, imutável de formas linguísticas sem que haja nenhuma motivação ideológica na base do fenômeno linguístico² ${ }^{2}$ Esta concepção, para o autor russo, é característica do espírito do racionalismo, predominante na segunda tendência do pensamento filosófico linguístico da época.

De acordo com Volóchinov (2017), o centro organizador de qualquer enunciado não está no interior, mas no exterior, no meio social que circunda o indivíduo. A língua

1Os dados foram coletados no mês de novembro de 2019 .

2 É importante destacar que Volóchinov não viveu a época da descoberta dos manuscritos saussurianos, então a sua leitura é centrada nas noções contidas na edição do Curso de Linguística Geral que, na época, representava a voz oficial de Saussure. 
se apresenta como um processo ininterrupto realizado por meio das relações de interação sociodiscursiva do falante. "As leis de formação da língua não são de modo algum individuais e psicológicas, tampouco podem ser isoladas da atividade dos indivíduos falantes. As leis da formação da língua são leis sociológicas em sua essência" (VOLÓCHINOV, 2017, p. 224).

Desse modo, Volóchinov (2017) argumenta que a língua entendida como sistema estável de formas normativas é apenas uma abstração científica, que a palavra em uso não se centra em si mesma, mas conserva com a realidade um vínculo estreito e que, separada da vida, a palavra perde o sentido, constituindo, assim, um ato bilateral: "na palavra, eu dou forma a mim mesmo do ponto de vista do outro e, por fim, da perspectiva da minha coletividade" (VOLÓCHINOV, 2017, p. 205).

Nesse contexto, Volóchinov rompe com o pensamento dualista (individual/social) de sua época sobre a língua. $\mathrm{O}$ enunciado é produto da interação entre indivíduos socialmente organizados, inseridos na história. Linguagem, consciência e cultura estão intrinsecamente relacionadas. O conteúdo da consciência, consoante o autor russo, reflete a dialética da história, e não mais a dialética da natureza. Os desejos, os sentimentos, o pensamento passam pelo estatuto do signo.

Signo e situação social são indissolúveis: todo signo é ideológico, os sistemas semióticos exprimem a ideologia e são, portanto, moldados por ela. Entretanto, os signos somente adquirem o seu valor semiótico na interação verbal. De acordo com Volóchinov (2013), o contexto extraverbal da enunciação é composto por três aspectos: 1) um horizonte espacial compartilhado por ambos os falantes; 2) o conhecimento e a compreensão comum da situação, igualmente compartilhada pelos interlocutores; 3) a valoração compartilhada pelos dois, em uma dada situação.

Em face disso, Volóchinov (2017) defende que todo enunciado é constituído em um contexto ativo e responsivo, ou seja, responde a algo, orienta-se para uma resposta e que toda compreensão é dialógica, pois sempre busca uma contrapalavra na palavra do falante.

Compreender um enunciado alheio significa orientar-se em relação a ele, encontrar para ele um lugar devido ao contexto correspondente. Em cada palavra de um enunciado compreendido, acrescentamos como que uma 
camada de nossas palavras responsivas (VOLÓCHINOV, 2017, p. 232).

O conceito de dialogismo é minuciosamente desenvolvido por Bakhtin. De acordo com o autor, o discurso é, por natureza, dialógico, e a unidade do discurso é o enunciado; portanto, todo enunciado é uma réplica do diálogo. "O discurso é a língua in actu" (BAKHTIN, 2016, p. 117). Nesse sentido, não é possível contrapor língua e discurso, visto que o discurso é tão social quanto a língua, e as formas de enunciado, assim como a língua, são sociais e igualmente determinadas pela comunicação. Dessa forma, a ideia de discurso monológico e enunciado neutro é recusada por Bakhtin (2016, p. 136): "nem de longe são neutros todos os fenômenos da língua (palavras, unidades fraseológicas, ou mesmo as formas morfológicas e sintáticas). Estas exalam estilos, a elas estão vinculadas certas apreciações tendenciais, ideológicas, sociais”.

Bakhtin (2016) defende que a seleção dos recursos linguísticos e estilísticos dos fenômenos da língua pelo sujeito é determinada por três aspectos: o conteúdo semântico objetal, ou seja, o direcionamento para o objeto do discurso; a expressividade, isto é, a expressão do enunciador, e, por fim, a relação com o interlocutor e com o discurso do outro. $\mathrm{O}$ caráter responsivo é, então, constitutivo do enunciado, qualquer enunciado pressupõe um interlocutor, cuja relação é elemento fundamental do discurso. "A relação com o interlocutor determina o discurso tanto quanto a relação com o objeto (com a realidade)", afirma Bakhtin (2016, p. 135).

Neste sentido, podemos pensar que toda e qualquer realidade é sempre indissociável da presença de um interlocutor e sua palavra, e, nesta fronteira, o sujeito concorda, discorda, reage e age, tornando-se único e singular. Portanto, tanto Bakhtin quanto Volóchinov rompem com o pensamento de sua época, na medida em que propõem uma dialética e não uma dicotomia entre social e individual. O enunciado é compreendido nas práticas sociais, portanto nas relações interativas concretas, e, desta forma, é uma unidade de sentido axiologicamente construída pelo falante num determinado contexto social, histórico e cultural. A palavra duma língua somente se torna palavra quando o falante a inscreve com sua intenção, com seu acento. 
individuais dos outros. Em certo sentido, essa experiência pode ser caracterizada como processo de assimilação - mais ou menos criador - das palavras do outro (e não das palavras da língua). Nosso discurso, isto é, todos os nossos enunciados (inclusive as obras criadas) é pleno de palavras dos outros, de um grau vário de alteridade ou de assimilabilidade, de um grau vário de aperceptibilidade e de relevância. Essas palavras dos outros trazem consigo a sua expressão, o seu tom valorativo que assimilamos, reelaboramos e reacentuamos (BAKHTIN, 2011, p. 294-295).

A atitude valorativa, de acordo com Cunha (2015, 2012), se aproxima da noção de ponto de vista, embora a noção de PDV não seja usada como conceito por Bakhtin. De acordo com a autora, o PDV é constituído dialogicamente, no confronto com outro PDV, somente existindo PDV porque há diversas formas de se posicionar em relação a uma mesma realidade. Diante disto, partindo da noção de ponto de vista, pode-se pensar em um sujeito heterogêneo, com múltiplas identidades, não existindo um sujeito da enunciação, mas figuras diferentes do sujeito, de acordo com o momento em que fala, com aquilo que fala ou que silencia e com a maneira como se relaciona com o discurso do outro.

Nesse sentido, o PDV é dinâmico e contingente, comporta movimentos e modificações, pode ser objeto de reavaliações, reacentuações, pode ser corrigido por outro em razão do lugar, do que se considera principal ou secundário. Por outro lado, pode se ter uma constância, ser compatível com um outro ou impedir de se ter um outro (CUNHA, 2014, p. 15).

Desta forma, podemos pensar que o enunciado é uma unidade de sentido constituída axiologicamente em uma situação interativa. No processo de interlocução, o enunciador ocupa uma posição responsiva e, portanto, valorativa, cujo eco demarca seu PDV. Sendo assim, as noções de valoração e de PDV estão intrinsecamente relacionadas às relações dialógicas da língua em suas diferentes dimensões.

As relações dialógicas são possíveis não apenas entre enunciações integrais (relativamente), mas o enfoque dialógico é possível a qualquer parte significante do enunciado [...]. Por isso, as relações dialógicas podem penetrar no âmago do enunciado [...]. Por outro lado, as relações dialógicas são possíveis entre os estilos de linguagem [...] Por último, as relações dialógicas são possíveis também com a própria enunciação como um todo [...] (BAKHTIN, 2015, p. 210211).

De acordo com Fiorin (2018), podemos pensar em três tipos de dialogismo. O dialogismo como princípio constitutivo da linguagem, ou seja, a maneira de funcionamento real do enunciado, cuja ordem não aparece no fio do discurso. $\mathrm{O}$ 
dialogismo como forma composicional, cuja ordem está no âmbito do visível, são as formas de absorção do discurso alheio representado ora pelo discurso objetivado, ora pelo discurso bivocal. E, por fim, o dialogismo como princípio de ação. Neste sentido, Bakhtin refuta a ideia tanto de um sujeito social, submisso às estruturas, quanto de um sujeito individual, autônomo em relação às estruturas, e defende a ideia de homem constituído discursivamente na e pela ação/relação com os outros.

\section{Gêneros e comentário on-line}

De acordo com Fiorin (2018), o ponto de partida da teoria bakhtiniana sobre o gênero é o vínculo intrínseco entre o uso da linguagem e as atividades humanas, considerando os enunciados no processo de interação. O estudo de Bakhtin não tinha como objetivo descrever os gêneros, mas compreender a vinculação do gênero com a sua esfera de atuação, procurando entender o seu processo de emergência e de estabilização. O gênero somente adquire sentido no âmbito da língua em ação.

De acordo com Bakhtin (2016), os diferentes campos da atividade humana estão relacionados ao uso da linguagem, e o emprego da língua no processo de comunicação é efetuado em forma de enunciados concretos e únicos, sejam orais ou escritos. Em cada esfera da atividade linguística, são elaborados tipos de enunciados relativamente estáveis, que são os gêneros. O autor destaca que a diversidade de gênero é infinita, porque tanto são inesgotáveis as possibilidades de atividade humana, quanto cada campo de atividade, cujo repertório do discurso é elaborado, cresce e se diferencia na mesma medida em que o campo se desenvolve e ganha complexidade.

De acordo com o autor russo, o gênero do discurso é composto por três elementos: o conteúdo temático, o estilo e a construção composicional, indissociáveis no conjunto do enunciado e determinados pela especificidade de cada campo comunicativo.

O conteúdo temático não está relacionado ao assunto específico de um texto, explica Fiorin (2018), mas é o domínio de sentido do gênero; uma carta de amor, por 
exemplo, apresenta como conteúdo as relações amorosas; a construção composicional compreende a maneira de organizar o texto em sua arquitetura, e o estilo está relacionado à seleção dos meios linguísticos, em termos lexicais, fraseológicos e gramaticais.

De acordo com Marcuschi (2008), se levarmos em consideração o gênero enquanto enunciado concreto, situado histórico e socialmente, e assim culturalmente sensível, atuando como instrumento comunicativo, cujo propósito específico é forma de ação social, é possível pensar, em certa medida, que, na emergência de um novo meio discursivo, surgem seus gêneros específicos, a exemplo da comunicação mediada por computador e os gêneros que nela residem.

Com o advento da internet, surgem outras formas sociais de interagir linguisticamente. Para Marcuschi (2008), nesta nova realidade, o estudo dos gêneros que surgem no meio eletrônico é relevante frente a quatro aspectos: primeiro, porque os gêneros digitais estão em desenvolvimento e em fase de fixação com uso cada vez mais generalizado; segundo, porque os gêneros digitais apresentam peculiaridades formais próprias, apesar de terem contraparte em gêneros prévios; terceiro, oferecem a possibilidade de repensar alguns conceitos tradicionais referentes à textualidade e, por fim, mudam sensivelmente nossa relação não apenas com a escrita, mas também com a oralidade, fato que nos convoca a repensá-las.

De acordo com Machado (2003), os gêneros digitais são originários das formas de linguagem visual, verbal, oral e escrita já existentes, entretanto a diferença de suporte implica na diferença de codificação, e, por sua vez, em uma diferença de compreensão e linguagem. Desta forma, para a autora, gêneros digitais são definidos como:

formas arquitetônicas cujas estruturas são modelizadas por linguagens
artificiais, criadas pela engenharia digital, para combinação e reprocessamento
de sistemas de escrita e de gêneros literários, discursivos; de gêneros
informativos da mídia impressa; da linguagem visual e do design gráfico; dos
gêneros audiovisuais do cinema, do rádio e da televisão. É todo um sistema de
troca e da engenharia que o viabiliza que passa a ser objeto do estudo dos
gêneros (MACHADO, 2003, p. 121).

De acordo com Cunha (2014), o gênero comentário on-line é uma prática discursiva com propósitos e regras próprias: a partir de um texto fonte, o enunciador constrói novos discursos, reacentuando aspectos outros para constituir seu PDV. Deste 
modo, é possível observar que o gênero comentário on-line é composto pelo entrecruzamento do dialogismo interdiscursivo e do dialogismo interlocutivo, cujo limite, em muitos casos, é difícil de determinar com precisão.

\section{Análise}

O corpus em análise é constituído pelo gênero comentário on-line. O comentário e suas respectivas réplicas foram originados a partir da postagem publicada na página do Facebook da revista Veja, no dia 17 de abril de 2019, sobre a afirmação direcionada pela ministra da Mulher, da Família e dos Direitos Humanos, Damares Alves, à deputada federal Tabata Amaral. O post rendeu, até o momento da coleta dos dados, 1,8 mil comentários e 659 compartilhamentos. Diante da amplitude do material, selecionamos, inicialmente, os comentários que possuíam réplicas. Em seguida, no segundo recorte, priorizamos os comentários cujas réplicas não ultrapassassem a quantidade máxima de 20 palavras, nem a mínima de 5 palavras. Do resultado desta leitura, selecionamos o corpus para análise, composto por um comentário on-line, elaborado a partir do post da revista Veja, e as réplicas a este comentário, somadas em um total de 17, todos transcritos aqui e disponibilizados também em anexo. Iniciemos, então, a análise do comentário e suas respectivas réplicas. ${ }^{3}$

Transcrição do texto contido no post, seguido do comentário inicial da interação e suas respectivas réplicas:

(A) Que deputada linda. Só de você já estar aqui. Não precisava nem abrir a boca. (reprodução, feita pela revista, da afirmação da ministra.)

(B) Damares Alves, Ministra dos Direitos Humanos, em estranho elogio à deputada Tabata Amaral. (descrição, feita pela revista, do trecho reproduzido)

(C) VCF: Qual o problema de um elogio. (comentário feito no post da revista e abaixo suas respectivas réplicas)

1. SR: Se ela fosse uma modelo de passarela, que não precisa abrir a boca,

3 Os nomes dos usuários foram transcritos apenas com as iniciais. 
talvez não tivesse problema. Mas como ela é deputada, em que o mais importante é a esfera intelectual, creio que tem sim.

2. VS: Não foi elogio, foi deboche. Elas não estão lá para cumprir padrões de beleza.

3. $A H$ : Local de trabalho. $100 \%$ inapropriado

4. EC: VS Com certeza! Assim como ela fez com Túlio Gadelha.

5. $A S$ : Em outras palavras: ela, como deputada, é só uma moça bonita...

6. $D B: \mathrm{O}$ problema tá no fato dela ficar tentando desqualificar a inteligência dos outros pela aparência, como se o que importasse fosse a beleza ou não, e não o que a pessoa tem a dizer (ㅇ)

7. VCF: Quanto bla bla Bla

8. $G C B C$ : É duro quando as pessoas não entendem...

9. $A S: V C F \&$

10. $S S$ : Até um elogio incomoda quem é maligno

11. KSL: VCF Você fica linda de boca fechada.

12. VCF: Ainnnn obrigada pelo "elogio" ๑)

13. $C D$ : $V C F$ você calada é linda!

14. VCF: emoticon dormindo

15. $C S$ : Para quem é do mal, até um simples elogio é ofensivo, aliás, nunca vi a ministra sem ofensiva com ninguém, sempre muito ponderada com as palavras.

16. VCF: $C S$ pois é.

17. $C G$ : $V C F$ Se fosse elogio nada. Mas foi deboche, ironia.

No comentário on-line, "qual o problema de um elogio", produzido pelo enunciador (C), é possível observar a presença do dialogismo interdiscursivo pelo processo de retomada da afirmação da revista Veja (B), cujo argumento central é defendido a partir da proposição de que a fala da ministra seria um estranho elogio. $\mathrm{O}$ PDV do enunciador $(C)$ é formulado a partir da construção da pergunta retórica, embora a expressão não esteja explicitamente grafada com o sinal de pontuação.

Segundo Volóchinov (2017), esse fenômeno linguístico se situa na fronteira entre o discurso alheio e o discurso autoral e muitas vezes integra diretamente este ou aquele. Em face disso, é perceptível a adesão inicial do enunciador (C) à voz da Veja (B), pois concorda com o fato de ser a afirmação de Damares um “elogio”. Entretanto, a pergunta sugere, ao mesmo tempo, um tom valorativo de contestação indicado pelo termo “problema”, cuja relação dialógica parece estar relacionada ao juízo de valor elaborado pela revista, no qual o dizer da ministra é qualificado como estranho (B).

De acordo com Bakhtin (2015, p. 223), “A transmissão da afirmação do outro em forma de pergunta já leva a um atrito entre duas interpretações [...] tendo em vista que não apenas perguntamos como problematizamos a afirmação do outro”. Dessa forma, no processo de retomada do discurso da Veja (B), ao interpelar a avaliação da revista, o 
enunciador expõe o seu PDV, respaldando de modo positivo a voz da ministra Damares (A). A este PDV (C), são direcionadas as réplicas, como veremos a seguir.

Na réplica 1, é possível perceber o entrelaçamento entre vozes na composição do PDV, cujas relações dialógicas marcam o percurso da argumentação. SR assume uma postura responsiva ao comentário $(\mathrm{C})$. De início, contesta-o diretamente, retornando à fala da ministra Damares: "Se ela fosse uma modelo de passarela, que não precisa abrir a boca, talvez não tivesse problema”, para, então, a partir disso, colocar em evidência o estatuto ofensivo do "elogio" à deputada Tabata: "Mas como ela é deputada, em que o mais importante é a esfera intelectual, creio que tem sim”.

Nas palavras de Bakhtin, ao se referir ao elemento expressivo do enunciado, "a relação valorativa do falante com o objeto do seu discurso (seja qual for esse objeto) também determina a escolha dos recursos lexicais, gramaticais e composicionais" (BAKHTIN, 2016, p. 47). Nesse sentido, pelo uso linguístico do recurso da analogia, o interlocutor constrói seu PDV pelo jogo de paralelos axiológicos, nitidamente demarcado, em que confronta duas vozes ideológicas divergentes: a sua e a do enunciador (C). É possível observar também que, na sequência enunciativa, o discurso alheio é, ao mesmo tempo, revestido de uma sutilidade irônica, processo pelo qual o interlocutor (1) acentua sua perspectiva crítica em relação à postura do enunciador $(C)$.

Na réplica seguinte (2), "Não foi elogio, foi deboche", a interlocução também é marcada pelo confronto nítido entre duas posições axiológicas discordantes, entretanto constituída por outra arquitetura dialógica. Pelo tom valorativo da negação, VS (2) refuta de maneira incisiva a postura exposta no comentário $(C)$, caracterizando a fala da ministra como deboche. É possível observar que o PDV do interlocutor (2) é nitidamente separado do PDV do enunciador $(C)$. Assim sendo, podemos pensar que o enunciado é constituído pela presença das relações dialógicas inerentes ao discurso objetivado ${ }^{4}$, tal como proposto por Bakhtin (2015), ou seja, há o conflito de vozes nitidamente demarcadas: o elogio e o deboche. Em seguida, "Elas não estão lá para cumprir padrões de beleza”, VS ratifica, em certo tom ríspido, a ideia já veiculada na primeira réplica (1): de que o dizer da ministra desvirtua o lugar político da deputada Tabata.

4 De acordo com Fiorin (2018), a negação é um exemplo de discurso objetivado em Bakhtin. 
Utilizando também o recurso da objetividade, a réplica 3, "Local de trabalho. 100\% inapropriado", sugere um certo distanciamento da cena de interlocução do debate, diferentemente das réplicas anteriores. Entretanto, é possível perceber no enunciado, embora sucintos, os ecos valorativos do discurso do outro, pois o interlocutor (3) também assume uma postura de desaprovação ante à afirmação da ministra Damares, em consenso com as réplicas precedentes. Nesse sentido, podemos entender o enunciado conforme Bakhtin (2011) quando afirma que, ao elaborar seu ponto de vista, o locutor dialoga com o discurso do outro em diferentes graus de alteridade, seja em relação de maior ou menor convergência ou divergência.

Em (4), EC se insere no diálogo pela interlocução direta com VS (réplica 2). O uso da expressão adverbial modalizadora “com certeza”, antecedido pela marcação do nome do usuário VS, revela a plena adesão do interlocutor à proposição de que a atitude da ministra é um deboche e não um elogio. Em seguida, "assim como ela fez com Túlio Gadelha”, o interlocutor (4) procura reforçar o argumento do deboche, inserindo no debate um outro evento político envolvendo a ministra, situação que avalia ser semelhante à da deputada Tabata.

É possível perceber, diante disso, que a réplica 4 é construída não apenas pela presença do dialogismo interlocutivo, mas também pelo dialogismo interdiscursivo, marcado pela alusão a outro evento constitutivo da memória discursiva: a referência a Túlio Gadelha. Consoante Volóchinov (2017), o horizonte valorativo é um conjunto de vivências e expressões cotidianas de caráter social, e os julgamentos de valor, por sua vez, determinam a escolha das palavras. Assim, ao fazer uso da alusão, o interlocutor (4) constrói o seu ponto de vista pela reintegração do discurso do outro (2), atribuindo-lhe credibilidade.

A réplica 5, “Em outras palavras: ela, como deputada, é só uma moça bonita...”, sugere uma intenção de síntese dos PDVs antecedentes. Na sequência enunciativa, a escolha do modalizador "em outras palavras", seguida do sinal de pontuação, dois pontos, direciona a expectativa do leitor para uma enunciação concludente. $\mathrm{O}$ tom valorativo incisivo no enunciado demarca o PDV, direcionando um posicionamento axiológico em concordância com a inadequação da fala da ministra Damares.

Em consonância, também, com os PDVs veiculados anteriormente, a réplica 6 
inicia seu argumento reportando-se ao enunciador do comentário (C). A interlocução é evidenciada pela retomada do termo "problema", constitutivo da pergunta retórica, "O problema tá no fato dela ficar tentando desqualificar a inteligência dos outros pela aparência, como se o que importasse fosse a beleza ou não, e não o que a pessoa tem a dizer (으” É Eossível perceber que o enunciador (6) reproduz um tom emotivo-volitivo nítido de objeção direcionado ao dizer da ministra Damares. Como forma de ressaltar o tom valorativo do seu PDV, finaliza sua réplica com o emoticon (de desaprovação), próprio da enunciação digital, cuja finalidade é ampliar a forma de expressão dos usuários.

Em seguida, a autora do comentário (C) intervém no debate e assume uma postura valorativa ofensiva, desmerecendo a fala dos internautas das réplicas anteriores: "Quanto bla bla Bla" (7). De uma maneira menos agressiva, o PDV seguinte (8), "É duro quando as pessoas não entendem...”, parece responder à intervenção da réplica 7 . Entretanto, embora o locutor inicie revestindo o enunciado de uma valoração asseverativa, o uso de reticências no fim da réplica deixa uma incompletude no discurso, como se quisesse se esquivar da responsabilidade enunciativa do seu dizer. À vista disso, o PDV aponta uma sequência enunciativa constituída por um movimento duplo de afluência e, ao mesmo tempo, de abjunção ao discurso exposto em (7).

Diferentemente, na réplica 9, o interlocutor convoca diretamente o enunciador do comentário (C), utilizando o recurso da marcação do nome do usuário "VSF", e, em seguida, usa exclusivamente o emoticon para marcar o seu posicionamento na interlocução. Pelo uso do emoticon que expressa vergonha, o interlocutor mostra sua rejeição à postura de anuência do seu enunciador ao discurso da ministra Damares.

Na réplica seguinte (10), "até um elogio incomoda quem é maligno", embora mantenha um distanciamento da cena de interlocução, SS indica uma clara adesão ao argumento exposto no comentário (C). O PDV é formulado pela retomada, com um certo tom valorativo de agressividade, do discurso religioso, marcado pelo termo "maligno". Na alusão ao discurso religioso, SS demarca de maneira visível o confronto de vozes ideológicas, resgatando as balizas morais entre o bem e o mal. O mesmo posicionamento axiológico é retomado mais à frente na réplica 15: "para quem é do mal, 
até um simples elogio é ofensivo, aliás, nunca vi a ministra sem ofensiva com ninguém, sempre muito ponderada com as palavras". Usando também como ponto de apoio argumentativo os valores religiosos, entretanto de maneira menos genérica, o interlocutor (15) defende explicitamente a ministra Damares, demarcando seu PDV pela concordância e, ao mesmo tempo, pelo respaldo do PDV exposto em (10).

É possível observar nas réplicas 11 "você fica linda de boca fechada" e 13 "você calada é linda”, respectivamente, a mesma arquitetura dialógica. Utilizando o recurso da marcação como modo de convocar diretamente a atenção do enunciador do comentário (C), os interlocutores retomam a voz da ministra Damares sobre a deputada, valorandoa ironicamente. Desse modo, demarcam seus PDVs assumindo uma posição contrária, ao buscar desestabilizar, pelo recurso da ironia, o ponto de vista (C).

Finalizando o debate, a réplica 17, "Se fosse elogio nada. Mas foi deboche, ironia.", é direcionada à pergunta do comentário $(C)$. É perceptível que o PDV é elaborado pelo processo de retomada do PDV expresso na réplica 2, e isso fica evidente pelo consenso com a caracterização da declaração da ministra como deboche e não como um elogio.

\section{Considerações finais}

A discussão empreendida nos possibilitou observar as diferentes relações axiológico-dialógicas estabelecidas entre o sujeito e a palavra alheia na construção do PDV em interações digitais. A responsividade linguisticamente concretizada entre o comentário $(\mathrm{C})$ e suas respectivas réplicas é constituída pela presença recíproca do dialogismo interdiscursivo e interlocutivo. No processo de retomada do discurso do outro, o enunciador acentua de formas diversas o seu ponto de vista, com graus vários de concordância ou discordância e, nesse sentido, revela os diferentes graus de alteridade em relação ao discurso do outro e o modo como, no embate de vozes ideológicas, cada enunciador ecoa índices valorativos numa relação de interação com a palavra alheia.

O olhar para as diferentes formas de idas e vindas à vista com a palavra do outro 
na construção do ponto de vista mostra algumas pistas sobre o entendimento da dimensão responsiva do enunciado como unidade de sentido, constituída axiologicamente em uma situação de interação verbal. Tal aspecto convoca a reflexão da noção de signo ideológico e da concepção de que a língua é o discurso em ato, propostas pelos linguistas russos.

Portanto, é possível dizer que o processo de produção de sentidos materializado linguisticamente pelo enunciador no mecanismo de negociação com o discurso do outro aponta caminhos no entendimento sobre o uso da língua em contextos de interações dialógicas, e, consequentemente, sobre a natureza axiológica da língua em sua dimensão valorativa, cujo âmbito apresenta terreno fértil para compreensão da questão do ponto de vista.

\section{Referências}

BAKHTIN, Mikhail. Os gêneros do discurso. Tradução de Paulo Bezerra. São Paulo: Editora 34, 2016.

BAKHTIN, Mikhail. Problemas da poética de Dostoiévski. $5^{\underline{a}}$ ed. Tradução de Paulo Bezerra. Rio de Janeiro: Forense Universitária, 2015.

BAKHTIN, Mikhail. Estética da Criação Verbal. 6ae ed. Tradução de Paulo Bezerra. São Paulo: Editora Martins Fontes, 2011.

CUNHA, Dóris de Arruda C. Discurso outro e ponto de vista na construção do gênero perfil jornalístico. Investigações, v. 28, p. 1-49, 2015.

CUNHA, Dóris de Arruda C. Reflexões sobre o ponto de vista e a construção discursiva de comentários de leitores na web. In: REINO, Lucas Santiago Arraes; BUENO, Thaísa (Org.). Comentários na internet. 1 ed. Imperatriz: UDUFMA, p. 11-22, 2014.

CUNHA, Dóris de Arruda C. Dialogismos e ponto de vista: um estudo da charge. Eutomia. Recife, v. 1, p. 244-263, 2012.

FIORIN, José Luiz. Introdução ao pensamento de Bakhtin. $2^{\underline{a}}$ ed. São Paulo: Contexto, 2018. 
MACHADO, Irene. Gêneros Digitais e suas fronteiras na cultura tecnológica. Revista

Educação E Tecnologia, no 6, p. 117-128, 2003.

MARCUSCHI, Luiz Antônio. Produção textual, análise de gêneros e compreensão. São Paulo: Parábola Editorial, 2008.

VOLÓCHINOV, Valentin. Marxismo e Filosofia da Linguagem. Tradução de Sheila Grillo e Ekaterina Vólkova Américo. São Paulo: Editora 34, 2017.

VOLÓCHINOV, Valentin. A construção dos enunciados e outros ensaios. Tradução de João Wanderley Geraldi. São Carlos: Pedro \& Jorge Editores, 2013.

\section{Anexos}

Figura 1: Post publicado pela revista Veja em sua página do Facebook

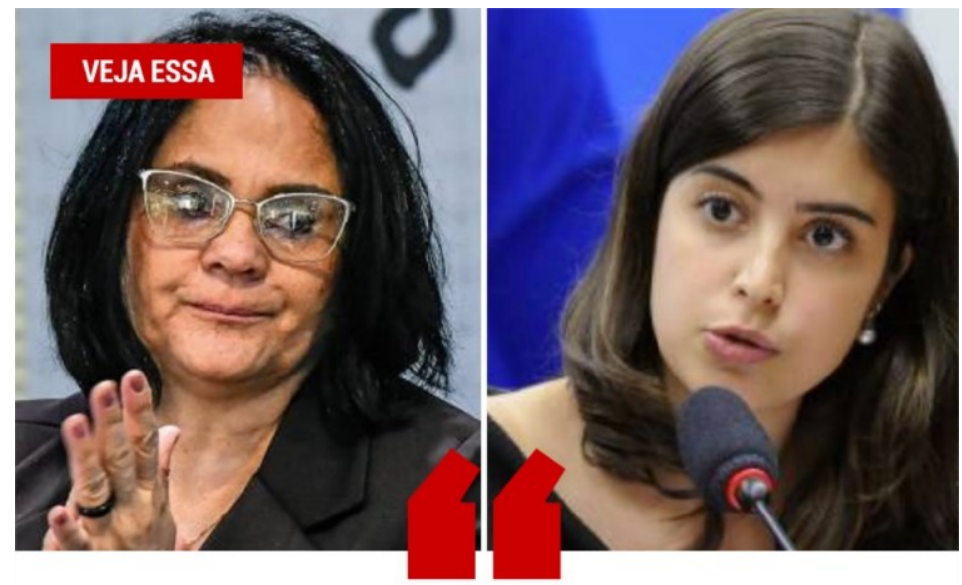

\section{Que deputada linda. Só de você já estar aqui. Não precisava nem abrir a boca}

DAMARES ALVES, ministra dos Direitos Humanos, em estranho elogio à deputada Tabata Amaral (PDT-SP)
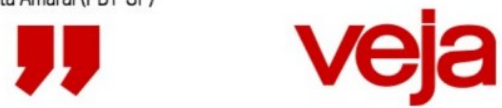

Fonte: Facebook https://www.facebook.com/Veja/posts/10156888517945617. Publicado em 17 de abril de 2019. Acesso em 17/04/2019. 
Figura 2: Comentário on-line e suas respectivas réplicas

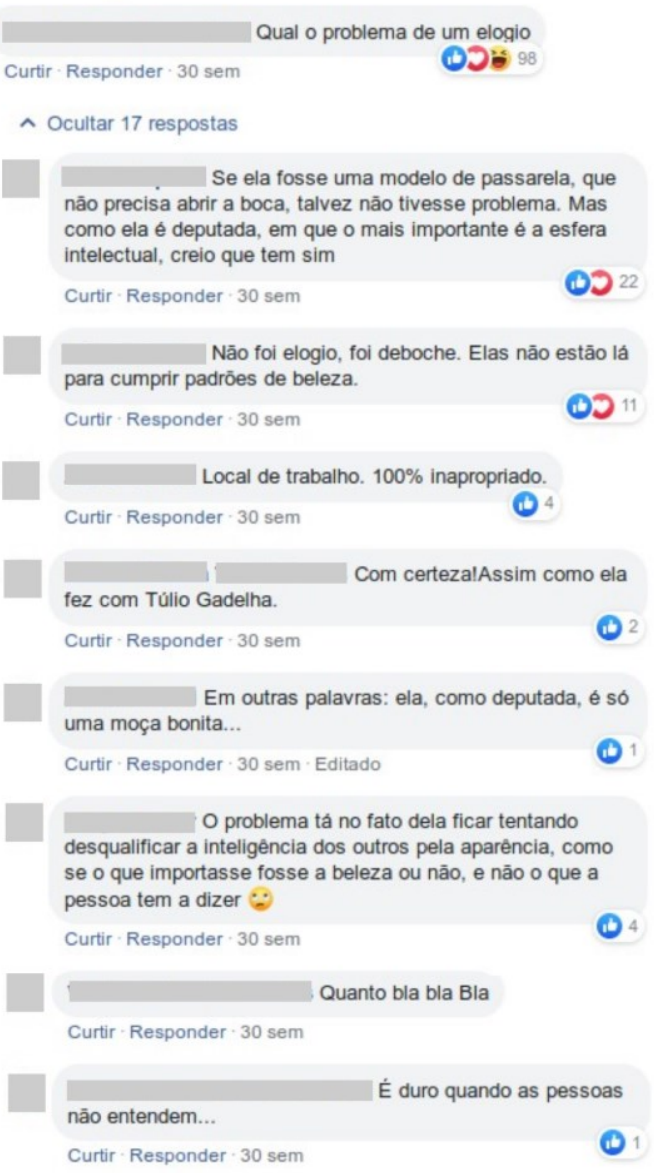

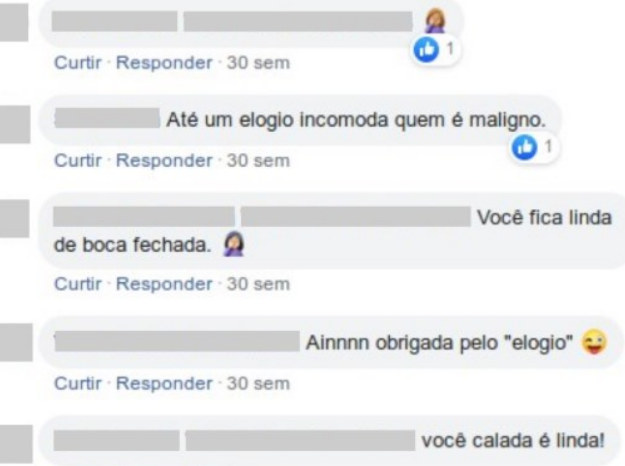

Curtir-Responder - 30 sem

(1) $=z z$

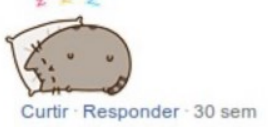

$\oplus$ Superfa

Para quem é do mal, até um simples elogio é ofensivo, aliás, nunca vi a ministra sem ofensiva com ninguém, sempre muito ponderada com as palavras. Curtir - Responder - 30 sem - Editado

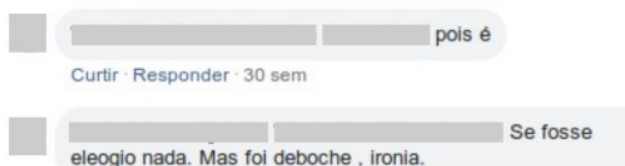

Curtir - Responder - 30 sem - Editado

Fonte: Facebook https://www.facebook.com/Veja/posts/10156888517945617. Publicado em 17 de abril de 2019. Acesso em 17/04/2019.

Recebido em 31/o8/2021.

Aprovado em o7/12/2021. 